\title{
PRESUPOSICIONES VIQUIANAS Y SU PERVIVENCIA EN LOS ORÍGENES DE LA INVESTIGACIÓN RETÓRICA DURANTE EL PERIODO DE WEIMAR
}

\author{
David L. Marshall \\ (Universidad de Pittsburgh, USA)
}

RESUMEN: Esta contribución explora el impacto actual del pensamiento de Vico en la obra de David Marshall examinando las presuposiciones viquianas que han pasado de su monográfico sobre Vico de 2010 al segundo libro que ha terminado recientemente, The Weimar Origins of Rhetorical Inquiry ("Los orígenes de la investigación retórica durante el periodo de Weimar").

Palabras ClaVe: Vico, $350^{\circ}$ Aniversario, Heidegger, Arendt, Benjamin, Warburg, interpelación, reconstrucción, sentido común, interpolación, barbarie del sentido, D.L. Marshall.

Vichian presuppositions and their persistence in The Weimar Origins of Rhetorical Inquiry ABSTRACT: This contribution explores the current impact of Vico's thinking on the work of David Marshall by examining the Viquian presuppositions between his 2010 monograph on Vico and the second book that he has recently finished, The Weimar Origins of Rhetorical Inquiry.

KEYWORDS: Vico, $350^{\text {th }}$ Anniversary, Heidegger, Arendt, Benjamin, Warburg, interpellation, reenactment, common sense, interpolation, barbarism of sense, D.L. Marshall.

\section{I presupposti vichiani e la loro presenza in The Weimar Origins of Rhetorical Inquiry}

RiASSUNTO: Questo contributo esplora l'attuale impatto del pensiero di Vico sull'opera di David Marshall, esaminandone i presupposti vichiani dalla sua monografia su Vico del 2010 al secondo libro, recentemente terminato, The Weimar Origins of Rhetorical Inquiry.

PAROLE ChiAVE: Vico, $350^{\circ}$ Anniversario, Heidegger, Arendt, Benjamin, Warburg, appello, ricreazione, senso comune, interpolazione, barbarie del senso, D.L. Marshall.

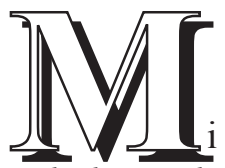

primer libro, Vico y la transformación de la retórica en la Europa de la Modernidad temprana, apareció en 2010. Fue una revisión de una tesis defendida en la Universidad Johns Hopkins en 2005, y el proyecto se originó en un estudio independiente que se llevó a cabo en Hopkins en otoño de 1998 con

Este artículo responde a una invitación expresa por parte de la Dirección de la Revista para este volumen especial por el $350^{\circ}$ Aniversario del nacimiento de G. Vico, habiendo superado los criterios de valoración y del proceso de aceptación. 
Nancy S. Struever y Vicki Hsueh. Recientemente he terminado un segundo libro, cuyo título provisional es Los orígenes de la investigación retórica durante el periodo de Weimar. Para mí, el mejor modo de reflexionar sobre la persistente influencia de Vico en mi investigación consiste en trabajar sobre este manuscrito destacando los puntos en los cuales se entromete en una historia que es bastante diferente. El segundo libro se centra en las recepciones y reinvenciones de la tradición retórica dentro de la Alemania moderna. Se enclava en la República de Weimar entre los años 1918 y 1933. Algunos de sus capítulos centrales están dedicados al pensamiento de Martin Heidegger, Hannah Arendt, Walter Benjamin y Aby Warburg. Acompañando a estos capítulos se encuentran tratamientos de los idiomas de la indagación retórica al acceso de los alemanes de Weimar y las resonancias del pensamiento de Heidegger, Arendt, Benjamin y Warburg en los contextos de los años posteriores a 1933 y a 1945. Abrazando esta obra, hay un primer capítulo que establece el problema y un capítulo de cierre que explora la línea de investigación identificada por el libro en el contexto contemporáneo del siglo XXI.

Durante el periodo de más o menos una década que he empleado en virar el foco de mi investigación desde los contextos del siglo XVIII en el sur de Europa hacia los del siglo XX en el norte de Europa y el siglo XXI en Norteamérica, he dedicado una cantidad significativa de tiempo y energía a aprovisionarme de nueva documentación y fuentes. Sin embargo, hasta donde he podido contar, hay al menos 26 puntos en los que Vico se deja notar en el manuscrito dedicado a Weimar. Para ilustrar "lo que Vico significa para mí", me propongo desarrollar una serie de estos lugares comunes. Mi hipótesis de trabajo se divide en tres partes: que Vico ha sembrado una cierta cantidad de presuposiciones básicas en mi pensamiento; que en la confección de la tradición de la investigación de la retórica durante el periodo de Weimar descrita en este segundo libro he prestado especial atención a las apropiaciones alemanas de esas presuposiciones básicas; y que dichas apropiaciones nos ayudan a entender las implicaciones de las presuposiciones viquianas en contextos diferentes de aquellos desde los que emergieron originalmente. A medida que repase estos lugares comunes, distinguiré cinco temas: interpelación, recreación, sentido común, interpolación y la barbarie del sentido. En lo que sigue, iré resolviendo cada uno de ellos poco a poco, haciendo referencia de vez en cuando a un manuscrito que no ha sido todavía publicado para establecer una relación de algún modo distanciada, impersonal o en tercera persona conmigo mismo.

Estimar el nacimiento del lenguaje en el trueno y el relámpago de Jove que interpeló a los bestioni resultó básico para la investigación viquiana en la Scienza nuova de 1744. El lenguaje comenzó en la metonímica e imaginativa escena de una tormenta que proclamó criaturas humanoides y sugirió implicar la existencia de un agente tras sus "actos". En el manuscrito de los «Orígenes de Weimar» encuentro ecos puntuales -en realidad, domesticaciones- de esta escenificación originaria de 
semiosis. Las domesticaciones más evidentes llegaron en la forma de la invocación que hace Aby Warburg de la explicación de la imaginación metonímica de Tito Vignoli. La obra Mito e scienza de Vignoli funciona a partir de la Scienza nuova de Vico. En lugar del trueno y el relámpago de Vico, Vignoli recurrió al tópos de un caballo aterrado por la voluntad que le atribuye a un pañuelo que se mece sobre un arbusto. ${ }^{1}$ El propio Warburg hizo suyo lo que se convertiría en un lugar común del siglo XIX: en lugar de perro de Darwin que se sobresalta por el movimiento "deliberado" de una sombrilla, toma una forma de vida que narrativiza el propósito para dar cuenta del golpe de una puerta por la corriente. ${ }^{2}$ Vignoli fue asimismo un canal en la derivación relacionada del concepto de Augenblicksgott (el «dios del momento») que Warburg se apropió de Hermann Usener (quien ha precisado el concepto en referencia a Vignoli, que a su vez estaba respondiendo a Vico). ${ }^{3}$ En la formulación de la sensibilización del arte de Warburg, el Augenblicksgott pasó a ser algo similar a una apariencia capaz de nombrarse a sí misma y ser su propia definición. Cuando todos los predicados de una apariencia se mostraban como esenciales para su definición, entonces esa aparición sensitiva corporeizada sería analítica (en lugar de ser sintética, en el sentido que esos términos son descritos dentro de la filosofía del lenguaje). En manos de Warburg se transforma un modelo inicialmente viquiano del llegar a ser de la semiosis. Warburg nos proporciona una explicación de la historia del arte como un tipo de teogonía pictórica en la que definiciones en disputa de las divinidades establecen un vocabulario cultural básico y discutido.

Uno de los desarrollos de las presuposiciones viquianas que encontramos en el modelo de Augenblicksgott de Warburg destaca que podría establecerse la diferencia entre enfrentarse a la aparición de una deidad y entregarse a ella imitándola -como una forma de camuflaje- ${ }^{4}$ Esto suscita una pregunta: "¿Cómo puede alguien responder a la interpelación?" Podría hacérsele frente abiertamente a la llamada, podría doblegarse a la llamada, o podría tratar de escabullirse de la escena de la interpelación reproduciendo su forma en otro lugar. En esta tercera opción, se asume la siguiente máxima: cuando se es interpelado por algo superior, no hay que

1. Giambattista Vico, Principi di scienza nuova d'intorno alla comune natura delle nazioni, en Opere, ed. a cargo de Andrea Battistini, Arnoldo Mondadori ed., Milán, 1990, § 379 [en adelante SN44]. Tito Vignoli, Mito e scienza: Saggio, Dumolard, Milán, 1879, p. 49.

2. Charles Darwin, The Descent of Man and Selection in Relation to Sex, John Murray, Londres, 1871, 1.67. ABY Warburg, «Reise-Erinnerungen aus dem Gebiet der Pueblo Indianer», en Werke in einem Band, editado por Martin Treml, Sigrid Weigel y Perdita Ladwig, Suhrkamp, Fráncfort del Meno, 2010, p. 578.

3. Aby Warburg, Heidnisch-antike Weissagung in Wort und Bild zu Luthers Zeiten, Carl Winters, Heidelberg, 1920, p. 28. HERMANN USENER, Götternamen: Versuch einer Lehre von der Religiösen Begriffsbildung, Friedrich Cohen, Bonn, 1896, p. 280. T. Vignol, Mito e scienza, cit., p. 171. Vignoli citaba la fisica poetica de Vico, para lo cual véase $S N 44, \S \S 687-702$. Véase también ERnSt CASSIRER, Sprache und Mythos: Ein Beitrag zum Problem der Götternamen, Teubner, Leipzig, 1925, p. 15.

4. Aby Warburg, Fragmente zur Ausdruckskunde, editado por Ulrich PFisterer y Hans Christian Hönes, De Gruyter, Berlín, 2015, § 46 (15 de enero de 1890). 
someterse o enfrentarse a ello; en lugar de eso, se trataría de encontrar a alguien inferior a quien interpelar del mismo modo. Hay un sentido en el que las presuposiciones viquianas que se ocupan de la verdad como algo cuya inteligibilidad reside en su capacidad de ser recreables son revisables invocando una personificación imaginada. Dicho con Max Fisch, puede afirmarse que el verum en el principio verum-factum de Vico significa «inteligible». ${ }^{5} \mathrm{La}$ inteligibilidad de algo es el grado según el cual -así como modos según los cuales- se puede hacer o realizar ese "algo" en cuestión. En la reinvención warburgiana que estoy precisando aquí, la interpelación se encarna en un arte figurativo donde algún personaje en una imagen hace un gesto por el cual otras figuras pueden responder sometiéndose, haciéndole frente o reaccionando. Puede entenderse el gesto mediante su repetición en el propio cuerpo. Estas son las cenni viquianas. En estas encarnaciones descubrimos que el principio verum-factum guarda una íntima conexión con la figuración. Las figuras deben distinguirse de los tropos. Más que realizar sustituciones, organizan patrones, y así comenzamos a ver que las intuiciones viquianas de Collingwood acerca de la danza como un lenguaje gestual original resultaban afortunadas: repetir un gesto es una cuestión de comprensión de sus figuraciones, es decir, el modo de realizar patrones en el tiempo y el espacio que marcan los movimientos del gesto. ${ }^{6}$ Una idea más: encontramos una distante aunque fascinante continuación de esta línea de indagación cuando leemos que, en el contexto de la visión computacional, algunos académicos se guían por la intuición de que los algoritmos pueden reconocer los límites de los objetos a través de la búsqueda de auto-similitudes: la forma que mantiene y "cierra el círculo" de los movimientos que ha iniciado supone un "objeto" definible. La simetría especular, por ejemplo, se discierne en la repetición que se muestra en un lado de un rostro y en el otro, en un lado del cuerpo y en el otro. Por tanto, las superficies de un rostro y de un cuerpo (en tanto en cuanto dos conjuntos de extremos reflejados o contrapuestos) son objetos anidados que influyen en el peso de la atención visual. ${ }^{7}$

En el marco de referencia viquiano, tenemos que imaginar la imitación como un tipo de recreación realizable que sitúa a los poetas en situaciones en las que se hace posible distanciarse de las convenciones establecidas. En esencia, esto fue una conceptualización del sentido común que no solo tiene una continuidad lite-

5. Giambattista Vico, De antiquissima Italorum sapientia ex linguae Latinae originibus eruenda, en Opere filosofiche, editado por Paolo Cristofolin, Sansoni, Florencia, 1971, pp. 62-65. MaX H. FISCH, «Vico and Pragmatism», en Giambattista Vico: An International Symposium, editado por Giorgio Tagliacozzo y Hayden V. White, The Johns Hopkins Press, Baltimore, 1969, p. 403.

6. R.G. CollingwoOd, Principles of Art, Oxford U.P., Oxford, 1938, p. 244.

7. Zygmunt Pizlo ET AL., Making a Machine that Sees Like Us, Oxford U.P., Oxford, 2014, p. 6: «[...] nuestra definición analítica de la forma será diferente. Sucede al contrario que en todas las principales definiciones analíticas de forma en las cuales la forma se define empleando la similitud de un objeto con otro. Nuestra nueva definición [de forma] emplea la similitud de un objeto consigo mismo. Esto se hace empleando las simetrías del objeto (sus auto-similitudes)». 
raria, sino también visual, que se apunta en el manuscrito sobre los «Orígenes de Weimar». De un modo extraño, aunque instructivo, las resonancias del pensamiento viquiano en el periodo de Weimar sugieren que el sensus communis de Vico se transforma en la Gerede de Heidegger. ${ }^{8}$ A primera vista esto parece claramente errado: en Vico, Homero demuestra que compartir conductas con otros conduce a la invención en lugar de a la repetición embrutecedora; en Heidegger, Gerede es un tipo de indigencia del discurso en la cual la urgencia por un contexto "primordial" original se ha perdido. El discurso deambula libre, sin situarse e irreal. Pero, si se observa con detenimiento, la historia es otra, especialmente en las obras tempranas de la década de 1920 que preceden a Sein und Zeit. «La charla insustancial» (Gerede) es una forma de «cotidianidad» (Alltäglichkeit), y la cotidianidad es una forma de acreción tópica en la que los similares se reúnen sin ser todavía disueltos en la precisión errónea de un medio estadístico. La población distribuida de "datos" reunida en la forma de la cotidianidad se convierte - como el Homero de Vico- en una fértil abundancia. Esta intuición se confirma en la continuación de Arendt: para ella, el sensus communis es un sentir kantiano por un público que agrupa respuestas potenciales en torno a una acción o un suceso. ${ }^{9}$ Como Heidegger predijo: lo posible es más constitutivo del ser que lo actual. ${ }^{10}$ En el Bilderatlas Mnemosyne de Walburg creo que encontramos una instanciación enriquecedoramente clarificadora de la topica sensibile de Vico. ${ }^{11}$ Recoger ejemplares visuales conforme a tópoi como «la continencia de Escipión» presenta un sentido común en tanto sensación común. En las tablas de imagen de Warburg deberíamos ver multitud de aparatos de formación para los sentidos. Ahí se aprendería a percibir las siluetas de un vocabulario cultural compartido. ${ }^{12}$ También en este punto Weimar confirma la hipótesis, al menos de forma provisional: el Apolo y Dafne de Wolfgang Stechow era una historia del arte warburgiano, pero, cuando Carl Linfert revisó el trabajo e incorporó la mitología viquiana, Walter Benjamin quedó cautivado y vio nuevas oportunidades para narrar la historicidad de la sensación. ${ }^{13}$

Una de las principales adiciones que los «Orígenes de Weimar» atribuye a Vico y la transformación de la retórica es un sentido más profundo en la reciproci-

8. SN44, §§ 142-143: el sentido común es «un giudizio senz'alcuna riflessione». MARTIN HEIDEGGER, Sein und Zeit: Erste Hälfte, Max Niemeyer, Tubinga, 1927, pp. 167-170.

9. Hannah Arendt, Lectures on Kant's Political Philosophy, editado por Ronald Beiner, University of Chicago Press, Chicago, 1982, pp. 70 y ss.

10. Martin Heidegger, «Dasein und Wahrsein Nach Aristoteles», en Vorträge, Vittorio Klostermann, Fráncfort del Meno, 2016, p. 97: «Möglichkeit—höhere Dignität als die Wirklichkeit».

11. $S N 44, \S 495$.

12. David L. Marshall, «Warburgian Maxims for Visual Rhetoric», Rhetoric Society Quarterly, 48, n. 4, 2018, pp. 352-379.

13. Wolfgang Stechow, Apollo und Daphne, Studien der Bibliothek Warburg, Leipzig, 1932; Carl Linfert, «Apollo und Daphne», Vossischen Zeitung, p. 330 (3 de diciembre de 1933), Unterhaltungsblatt, 29-30; WALTER Benjamin, Gesammelte Briefe, editado por Christoph Gödde y Henri Lonitz, Suhrkamp, Fráncfort del Meno, 1997, pp. 4.318-4.319. 
dad entre el ingenium como capacidad para conectar lo diverso y el iudicium como capacidad para diferenciar lo cercano. A este respecto, la articulación de la imaginación como interpolación de Benjamin es una de las revisiones más precisas de una presuposición viquiana. En 1940, cuando afirmó que se daba una ocluida y decisiva "filiación" por su trabajo -el ensayo Kunstwerk, en particular- que se remontaba a través del escritor del siglo XIX, Carl Gustav Jochmann, hasta Vico, Benjamin subrayaba la parte de Vico que destacó la primacía de la imaginación como una facultad del alma humana. ${ }^{14}$ Pero si el ingenium estaba en el corazón de la explicación de la imaginación de Vico, entonces Benjamin estaba llevando a efecto una inversión muy específica de Vico cuando, en su propia definición de «imaginación» (Phantasie), la caracterizaba sobre todo lo demás como una capacidad para la interpolación. El ingenium viquiano era una capacidad para unir lo que parecería desconectado, pero la Phantasie benjaminiana era una capacidad parecida para diferenciar lo que aparentaba ser inmediato. ${ }^{15}$ En Einbahnstraße, Benjamin ha sostenido que «la facultad de la imaginación es un talento para interpolar lo infinitamente pequeño, para descubrir en cualquier intensidad dada una plena nueva abundancia en tanto extensión». ${ }^{16}$ «Interpolar» (interpolieren) era precisamente la metáfora adecuada aquí. Para Benjamin, el verbo denota la dilación de un punto en la línea que ahora se extiende entre dos puntos. Un ejemplo de esto era sencillamente la práctica de la composición de Marcel Proust: cuando recibía las pruebas, no aplicaba correcciones. Proust tomaba cada punto y seguido como marcador de una oportunidad para inferir una conexión perdida entre una frase y otra. ${ }^{17}$ Acercándose al vacío entre frases revelaría un espacio que rellenar. Una vez más, podemos explorar la intuición en algún lugar dentro del pensamiento germanófono del siglo XX. Ernesto Grassi contribuía a esta continuidad viquiana-benjaminiana cuando destacaba el papel de la Differenzierung. ${ }^{18}$ La diferenciación es la labor temática que despierta la sensación desde su delicuescencia en la categoría de cotidianidad que ha pasado a estar comprometida con la supresión estadística de su propia abundancia.

Dentro de los límites de la propia Scienza nuova de 1744, el concepto de una barbarie del senso queda sutilmente aludido como la reversión de una barba-

14. Walter Benjamin, «Rückschritte der Poesie», en Gesammelte Schriften, Suhrkamp, Fráncfort del Meno, 1962, p. 2.584, donde Benjamin rastreó la noción de Jochmann de «Phantasie als das "urprüngliche Seelenvermögen"» hasta Vico.

15. $S N 44, \S 699$ : «l'ingegno altro non è che lavoro d'intorno a cose che si ricordano».

16. Walter Benjamin, Einbahnstraße, en Gesammelte Schriften, cit., 1972, p. 4.117: «das Vermögen der Phantasie ist die Gabe, im unendlich Kleinen zu interpolieren, jeder Intensität als Extensivem ihre neue gendrängte Fülle zu erfinden».

17. ID., «Zum Bilde Prousts», en Gesammelte Schriften, cit., p. 2.312.

18. ERnesto Grassi, «Über das Problem des Wortes und des individuellen Lebens: Erwägungen aus der italienischen Überlieferung», Geistige Überlieferung, 2, 1942, p. 21 y p. 60 -«wer sich wundert kommt zur Erkenntnis seines Nichtwissens, geht zum Fragen über, er wird aus der Gleichgültigkeit herausgerissen, es eröffnet sich ihm eine Welt der Differenzierung, die er bis dahin nicht ahnte»-. 
rie della riflessione que se da una y otra vez en momentos de agotamiento cultural, cuando los conceptos pueden ser desplegados con tal facilidad que adquieren un escaso o ningún arraigo en las mentes que los fingen. Se trata de mentes que pueden ignorar conceptos incluso mientras los emplean para realizar afirmaciones sobre los demás en exhibiciones de una insinceridad harto elegantes. ${ }^{19}$ En la reproducción de este fragmento que consta en los «Orígenes de la investigación retórica», Walter Benjamin nos proporciona un sentido mucho más preciso acerca de lo que podría ser realmente este proceso de agotamiento cultural y renovación. En la lectura que hace del «Erfahrung und Armut» de Benjamin, Linfert ha destacado lo que considera la concepción positiva de barbarie del artículo. ${ }^{20}$ Como vimos arriba, Vico fue en su momento una de las primeras conexiones entre Linfert y Benjamin, y creo que deberíamos considerar esto como una licencia para explorar la lectura que hace Benjamin, en el contexto posterior a la finalización de la I Guerra Mundial, de las interrelaciones entre lenguaje, experiencia y medios de comunicación en términos de un retorno a la viquiana barbarie del sentido. ${ }^{21} \mathrm{La}$ cuestión esencial es relativamente simple, incluso admitiendo lo extensivo de sus implicaciones: en el contexto de una crisis cultural de posguerra en la que los viejos nombres para las experiencias empezaban a vaciarse de sentido, las nuevas tecnologías de los medios de comunicación -como las cámaras fotográficas o cinematográficas- brindaban oportunidades renovadas para nombrar experiencias a través de la posibilidad de prestarles atención desde la especificación de nuevos parámetros sensitivos. Este barbarismo de sentido restituido se torna en un conjunto de preguntas más precisas, tales como, por ejemplo,

«en el amanecer de la Revolución Rusa, ¿cómo puede alguien usar una cámara para capturar con intención comunicativa el ánimo, la escena y los movimientos de la despedida de una reunión política que se realiza desde el desagrado?»».22

En esta discusión tremendamente resumida que he ofrecido aquí sobre los nodos centrados en la interpelación, recreación, sentido común, interpolación y barbarie del sentido solo podemos si acaso atisbar la continuidad de la presuposición viquiana en el contexto de Weimar. Cualquier exploración aceptable de estos temas requiere un libro. Quizás Los orígenes de la investigación retórica durante el periodo de Weimar será ese libro -o, al menos, un modo de avanzar hacia él-. A pesar

19. $S N 44, \S 1.106$.

20. Linfert ha empleado la frase «positive Begriff des Barbarentums» en una carta a Benjamin fechada en el 12 de diciembre de 1933, y la respuesta de Benjamin llegó el 17 del mismo mes. W. Benjamin, Gesammelte Briefe, p. 4.319. 21. Walter Benjamin, «Erfahrung und Armut», en Gesammelte Schriften, pp. 2.213-2.219.

22. La formulación es mía, pero el ejemplo procede de Osip Brik, «Selected Criticism, 1915-1929», October, 134, 2010, p. 103. 
de todo, el punto más profundo sostiene lo siguiente: el trabajo de Vico sigue siendo un repertorio de formulaciones cautivadoras que pueden transponerse y perseguirse en una gran variedad de contextos. Vico continúa siendo un teórico por excelencia: sus mejores pensamientos pasan a ser presuposiciones que hacen visibles los mejores pensamientos de otros y lo organiza en un repertorio de opciones para la investigación.

[Trad. del inglés por Pablo Badillo O'Farrell]

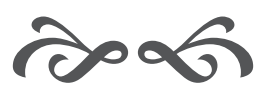

